\title{
PENGUASAAN ASET DAN STRUKTUR PEMBIAYAAN USAHA PENANGKAPAN IKAN TUNA MENURUT MUSIM YANG BERBEDA
}

\author{
Rizki Aprilian Wijaya, Hakim Miftakhul Huda, dan Manadiyanto \\ Balai Besar Penelitian Sosial Ekonomi Kelautan dan Perikanan \\ JI. KS. Tubun Petamburan VI Jakarta 10260 \\ Telp. (021) 53650162, Fax. (021)53650159 \\ Email: : rizkiaprilian@yahoo.co.id
}

Diterima 22 Februarui 2012 - Disetujui 3 Desember 2012

\begin{abstract}
ABSTRAK
Tulisan ini menyajikan struktur pembiayaan usaha penangkapan ikan tuna di Kota Bitung. Tujuan dari penulisan makalah ini adalah untuk mengetahui biaya investasi yang dibutuhkan, struktur pembiayaan usaha berdasarkan perbedaan musim ikan dan ukuran kapal, serta prospek pengembangan usaha. Penelitian menggunakan metode survei. Pengumpulan data menggunakan teknik wawancara terhadap pemilik kapal. Analisis data menggunakan metode statistik deskriptif dan analisa finansial. Hasil analisis menunjukan bahwa biaya total armada tuna mengalami peningkatan pada saat musim paceklik dan penerimaan mengalami peningkatan pada saat musim puncak ikan. Ukuran kapal yang digunakan berhubungan positif dengan biaya total, penerimaan dan pendapatan usaha. Berdasarkan analisa kelayakan usaha, ukuran kapal < 5 GT lebih layak secara ekonomi dibandingkan dengan kapal berukuran 5-10 GT. Implikasi kebijakan yang disarankan adalah menciptakan iklim investasi yang baik untuk penangkapan ikan tuna dengan batasan ukuran kapal < $10 \mathrm{GT}$ melalui skema kerjasama antara nelayan lokal dan investor yang berminat dengan prinsip bagi hasil yang adil.
\end{abstract}

Kata Kunci: pembiayaan usaha, perikanan tuna, musim, penguasaan aset, Kota Bitung

Abstract: Asset Acquisition and Financial Structure of Tuna Fishing According to Different Season. By: Rizki Aprilian Wijaya, Hakim Miftakhul Huda, dan Manadiyanto.

This paper presents the asset acquisition and financial structure of tuna fishing in the Bitung City. Purpose of this paper was to determine of the required investment costs and financing structure based on difference season and size of the vessel, as well as the prospects for business development. The research employs survey method. Data were collected by using interview techniques to a number of vessel owners. Data analysis uses descriptiv statistics method and financial analysis. Results of the analysis showed that total cost of the fleet has increased during bad season and revenues increased during peak season. Size of the vessels used were a positively associated with total cost, revenue and operating income. Based on feasibility analysis, vessel size of $<5$ GT was more economically viable than the vessel size of 5-10 GT. Policy implication suggested is to create a favorable investment climate environment for tuna fishing vessel size limit $<10$ GT through estabilismeant meat cooperative scheme between local fisher and investor according to the principle of equitable sharing.

Keywords: business financing, tuna fishery, season, assets, Bitung City 


\section{PENDAHULUAN}

Upaya peningkatan sektor kelautan dan perikanan sebagai sumber pertumbuhan ekonomi utama saat ini tetap menjadi fokus utama yang dilakukan oleh Kementerian Kelautan dan Perikanan. Program industrialisasi perikanan yang telah digulirkan sejak tahun 2011 bertujuan untuk meningkatkan kesejahteraan masyarakat sektor kelautan dan perikanan, baik nelayan pesisir, laut dan perairan lainnya, pembudidaya, pelaku pengolahan serta stakeholders lainnya melalui peningkatan nilai tambah industri. Salah satu komoditas utama program industrialisasi perikanan yang akan dikembangkan adalah komoditas ikan tuna yang sebagian besar produksinya berbasis di wilayah timur Indonesia. Ikan tuna telah dikenal sebagai komoditas ekspor perikanan primadona Indonesia dan penyumbang devisa terbesar kedua setelah udang (Dahuri, 2008). Sifat dari ikan tuna sendiri merupakan jenis ikan oseanik yang berupaya jauh (highly migratory species) berenang ribuan mil setiap tahunnya melalui Zona Ekonomi Eksklusif (ZEE) dari negaranegara pantai dan melintasi wilayah-wilayah laut bebas. Komoditi ekspor ikan tuna Indonesia meliputi Madidihang/Yellowfin tuna (Thunnus albacares), Tuna Mata Besar/Bigeye tuna (Thunnus obesus), Tuna Sirip Biru/Southern bluefin tuna (Thunnus macoyii), Albakor/ Albacare tuna (Thunnus alalunga), Cakalang/ Skipjack tuna (Katsuwonus pelamis) (Suharno dan Santoso, 2008).

Kota Bitung dikenal sebagai lokasi sentra produksi perikanan tangkap skala industri. Sekitar 70\% aktivitas industri di Provinsi Sulawesi Utara terkonsentrasi di Kota Bitung yang sebagian besar merupakan industri pengolahan ikan yang berorientasi ekspor (Apsari, 2009). Komoditas hasil tangkapan utama di Kota Bitung adalah ikan pelagis besar dari jenis ikan tuna dan cakalang. Data menunjukan, khusus untuk volume produksi ikan tuna ekor kuning dalam lima tahun terakhir yaitu Tahun 2007 hingga 2011 mengalami peningkatan sebesar $22 \%$ dari 37.500 ton menjadi 48.000 ton (Dinas Kelautan dan Perikanan Kota Bitung, 2012).
Aktivitas Bongkar muat ikan di Pelabuhan Perikanan Kota Bitung saat ini mencapai 50 ton per hari (Poernomo, 2006). Perbedaan musim dan skala armada penangkapan merupakan salah satu penyebab tinggi atau rendahnya produksi ikan tuna di Kota Bitung. Jika dilihat dari jumlah armada penangkapan, sejak awal tahun 2000 , armada penangkapan mengalami peningkatan setiap tahunnya hingga mencapai sekitar 1.200 unit kapal yang sebagian besar didominasi oleh armada kapal berukuran 5 - 10 GT (Dinas Kelautan dan Perikanan Kota Bitung, 2012).

Berdasarkan hal tersebut maka kajian tentang struktur pembiayaan usaha penangkapan ikan tuna berdasarkan perbedaan musim penangkapan dan penguasaan aset berdasarkan ukuran kapal, kebutuhan investasi aset dalam melakukan usaha penangkapan ikan tuna menjadi menarik untuk dikaji. Selain itu, perlu juga dilihat besarnya pembiayaan yang dikeluarkan dalam melakukan operasi penangkapan sehingga pada akhirnya dapat diketahui apakah usaha penangkapan ikan tuna memang layak secara ekonomi.

Penulisan makalah ini bertujuan untuk mengetahui kebutuhan investasi usaha penangkapan ikan tuna, mengetahui struktur pembiayaan usaha penangkapan ikan tuna berdasarkan musim, mengetahui struktur pembiayaan usaha penangkapan ikan tuna berdasarkan penguasaan aset di Kota Bitung dan mengetahui prospek pengembangan usaha penangkapan ikan tuna di Kota Bitung.

\section{METODOLOGI}

\section{Lokasi dan Waktu Penelitian}

Penelitian dilakukan di Kelurahan Batu Lubang Kecamatan Lembeh Selatan Kota Bitung Provinsi Sulawesi Utara. Alasan pemilihan lokasi karena wilayah ini merupakan sentra produksi perikanan tangkap ikan tuna skala kecil di Kota Bitung serta dapat dianggap mewakili tipologi perikanan tangkap pelagis besar. Penelitian ini dilakukan pada Bulan April Tahun 2011. 


\section{Metode Pengumpulan Data}

Penelitian menggunakan teknik survei lapang dengan metode pengumpulan data yang digunakan untuk wawancara kepada responden adalah metode non random purposive sampling. Purposive sampling merupakan metode pengambilan data dengan teknik responden dipilih secara sengaja untuk memenuhi tujuan tertentu (Fauzi, 2001). Responden yang dipilih merupakan pemilik kapal armada penangkapan ikan tuna dengan ukuran kapal < 5 GT dan 5 - 10 GT. Jumlah responden yang diwawancara adalah sebanyak 37 orang.

Sumber data yang dipergunakan dalam penelitian ini adalah data primer dan data sekunder. Pengumpulan data primer menggunakan teknik wawancara kepada responden dengan menggunakan alat bantu kuesioner terstruktur dan melalui pengamatan langsung di lapangan. Data primer yang dikumpulkan berupa data investasi usaha, biaya tetap usaha, biaya tidak tetap usaha dan penerimaan usaha penangkapan ikan tuna dalam jangka waktu satu tahun. Data sekunder merupakan data yang diterbitkan atau digunakan oleh organisasi yang bukan merupakan hasil olahan sendiri (Soeratno dan Arsyad, 2003). Data sekunder yang dikumpulkan berupa data statistik perikanan yang diperoleh dari Dinas Kelautan dan Perikanan Kota Bitung.

\section{Metode Analisis Data}

Unit analisis yang digunakan adalah satu armada penangkapan ikan tuna di Keluarahan Batu Lubang yang yang mewakili kondisi usaha masyarakat tipologi perikanan tankap pelagis besar. Proses pengolahan data dilakukan secara tabulasi dengan menggunakan program aplikasi Microsoft Access. Data yang telah ditabulasi kemudian dianalisis secara statistik deskriptif dengan maksud untuk memberikan gambaran secara rinci keadaan struktur kebutuhan investasi, biaya tetap, biaya tidak tetap, penerimaan dan analisa ekonomi penangkapan ikan tuna.
Perhitungan analisa usaha menggunakan analisa finansial. Perhitungan analisa finansial dilihat dari sudut orang yang berinvestasi pada usaha penangkapan ikan tuna. Dalam analisa finansial harga yang digunakan adalah harga pasar. Analisa finansial yang dilakukan adalah berupa rasio kelayakan usaha ( $R$ / $C$ ratio), rasio pengembalian investasi (Pay back periode / PP), dan rasio laba atas usaha (Return of investment / ROI). Rasio kelayakan usaha merupakan perbandingan antara total penerimaan dengan total biaya (Riyanto, 2001). Rasio pengembalian investasi merupakan suatu periode yang diperlukan untuk menutup kembali besaran investasi yang telah dikeluarkan. Rasio pengembalian investasi dihitung dengan membandingkan total investasi dengan pendapatan bersih. Rasio laba atas usaha menunjukan tingkat kemampuan dari modal usaha perikanan yang diinvestasikan untuk menghasilkan keuntungan netto. Rasio laba atas investasi dihitung dengan membandingkan pendapatan bersih dengan total investasi.

Keuntungan usaha dihitung berdasarkan besarnya penerimaan setelah dikurangi dengan biaya yang dikeluarkan untuk proses produksi baik tetap maupun tidak tetap (Soekartawi, 2003). Keuntungan usaha dibedakan berdasarkan status pekerjaan sebagai pemilik kapal, nahkoda, dan Anak Buah Kapal (ABK). Pola bagi hasil usaha penangkapan disajikan dalam Gambar 1.

\section{HASIL DAN PEMBAHASAN}

\section{Kebutuhan Investasi Penangkapan Ikan Tuna}

Usaha penangkapan ikan tuna di Kelurahan Batu Lubang memerlukan sejumlah pengeluaran biaya untuk investasi dan operasional. Biaya investasi merupakan seluruh biaya yang dikeluarkan mulai usaha tersebut dilaksanakan sampai usaha tersebut mulai beroperasi (Choliq et al., 1999). Kebutuhan investasi tersebut diantaranya berupa kapal, mesin, alat penangkapan ikan berupa pancing ulur (Hand line) dan peralatan tambahan lainnya. 


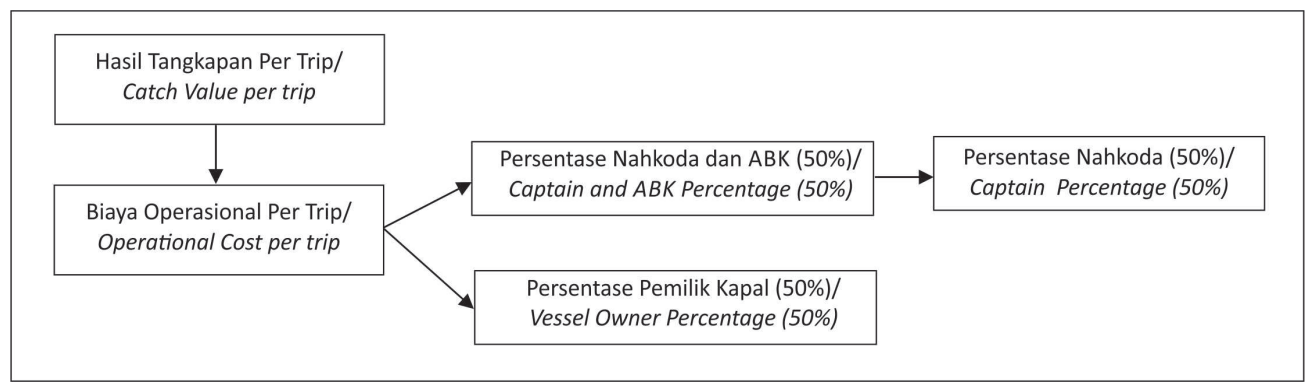

\section{Gambar 1. Pola Bagi Hasil Usaha Penangkapan Ikan Tuna di Kota Bitung, 2011 Figure 1. Profit Sharing Pattern Tuna Capture Business in Bitung City, 2011}

Sumber: Data Primer, 2011 (diolah) / Source: Primary data, 2011 (processed)

Jenis ukuran kapal yang digunakan oleh nelayan tuna di Kota Bitung yaitu kapal berukuran < 5 GT dan 5-10 GT yang termasuk ke dalam nelayan skala kecil. Terdapat dua jenis kapal yang biasa digunakan yaitu kapal "pamo" dan kapal "pamboat". Kapal "pamo" memiliki sayap (semacam sirip) di kedua sisinya yang berukuran lebih kecil serta memiliki stabilitas yang lebih tinggi dibandingkan dengan kapal "pamboat". Pengadaan kapal dapat dilakukan dengan membeli kapal jadi yang didatangkan dari luar daerah dan merakit kapal sendiri dengan menggunakan jasa pembuat kapal lokal. Merakit kapal sendiri merupakan salah satu strategi untuk menekan biaya investasi kapal.

Investasi yang dibutuhkan untuk usaha penangkapan tuna di Kota Bitung pada ukuran kapal < 5 GT adalah sebesar 55 jutaan dan ukuran kapal 5 - 10 GT adalah sebesar 200 jutaan (Tabel 1). Sebagian besar kapal yang digunakan bermesin dalam dengan kemampuan mesin berkisar antara $15-125$ daya kuda (PK) yang disesuaikan dengan ukuran kapal. Pengoperasian penangkapan dilakukan dengan menggunakan pancing yang diberi umpan (Hand line) dimana satu unit armada penangkapan membutuhkan 6 - 12 alat pancing. Satu unit alat pancing lengkap membutuhkan biaya sekitar Rp. 250.000 Rp. 300.000. Ukuran ikan tuna yang tertangkap dengan pancing sangat bervariasi, dari yang kecil sampai sangat besar (lebih dari $60 \mathrm{~kg}$ / ekor).
Metode penangkapan ikan tuna agar lebih efisien adalah dengan bantuan rumpon ikan laut dalam (Ponton/Rompong) pada wilayah tangkapan (Fishing ground) ikan tuna Jenis ikan pelagis besar tuna memiliki sifat yang mudah tertarik dan berkumpul di sekitar benda - benda yang terapung di laut (Marcille et al., 1984; Nugraha, 2008). Investasi untuk rumpon berkisar antara $30-60$ juta per unitnya. Harga yang tinggi tersebut sebagian besar digunakan untuk biaya tali tambat hingga ke dasar yang dalamnya hingga 200 - 1000 meter. Sebagian besar pelaku usaha penangkapan ikan tuna di Kota Bitung saat ini belum memiliki rumponnya sendiri, sehingga dalam operasi penangkapan menumpang pada rumpon nelayan lain. Diatas rumpon juga terdapat rumah untuk para penjaga rumpon, dimana dalam satu bulan mendapatkan gaji dari pemilik rumpon. Selain mendapatkan gaji, penjaga rumpon juga berhak untuk memancing tuna sendiri yang hasilnya nanti akan dititipkan pada kapal yang menangkap di rumponnya.

Peralatan penunjang palka kapal dibutuhkan untuk menyimpan ikan tuna hasil tangkapan. Kapal berukuran < 5 GT hanya dapat menampung sedikit ikan dibandingkan dengan kapal berukuran 5-10 GT sehingga palka yang dapat dibuat hanya 2 unit. Alat komunikasi yang dipakai pada kapal penangkap ikan tuna menggunakan radio pemancar yang dapat dibedakan menjadi dua jenis yaitu radio pemancar frekuensi tinggi 


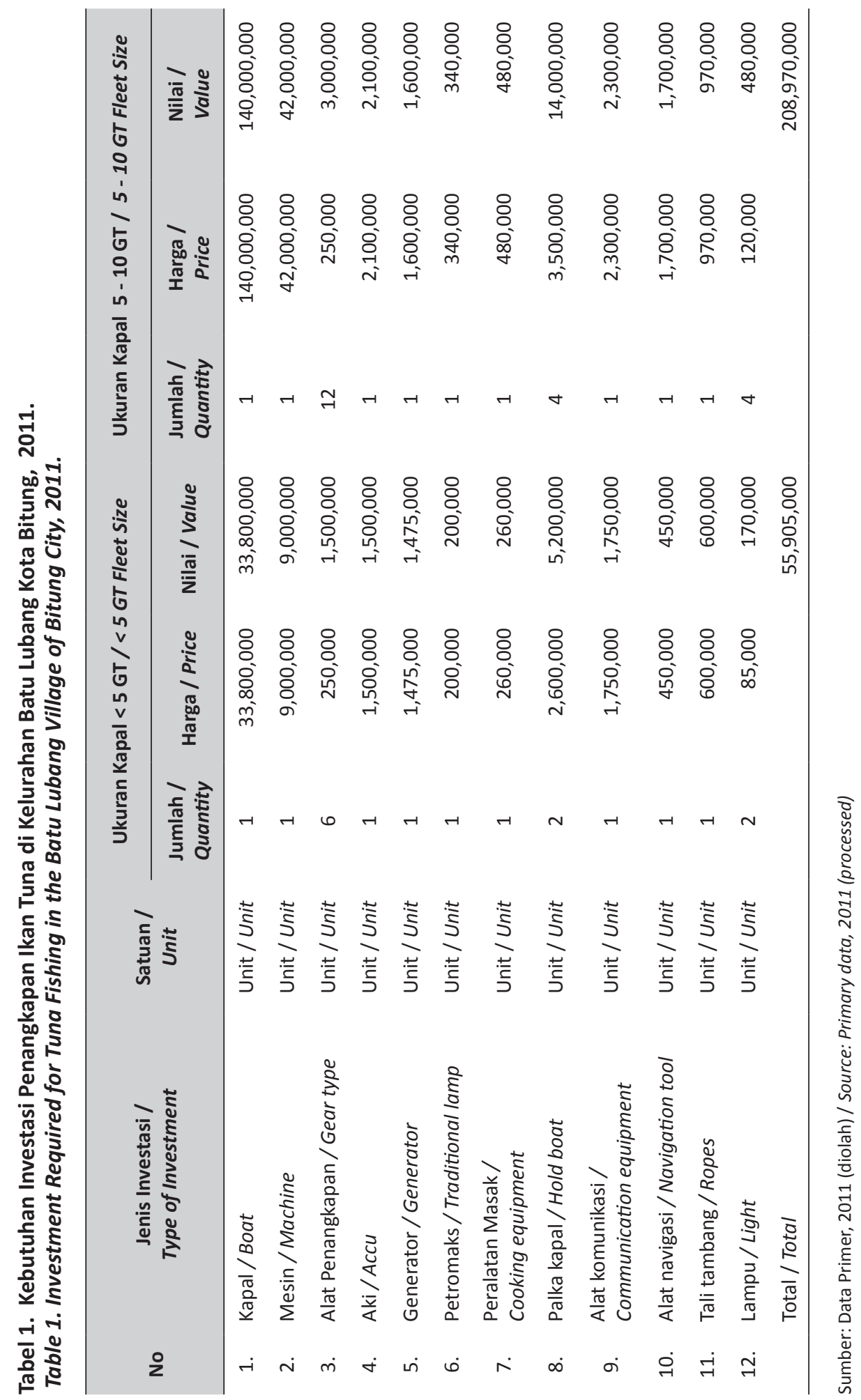


hingga dapat mencapai daratan dari tengah laut dan radio pemancar frekuensi rendah yang hanya dapat digunakan antar sesama kapal pada saat ditengah laut. Alat navigasi yang digunakan oleh kapal berukuran < 5 GT berupa alat kompas sederhana dan sangat mengandalkan kemampuan dan kelihaian nahkoda. Sementara pada ukuran kapal 5 - 10 GT memerlukan tambahan alat navigasi Global Positioning System (GPS).

\section{Struktur dan Pembiayaan Usaha Berdasarkan Musim dan Penguasaan Aset}

Operasi penangkapan memerlukan lama melaut antara 5-14 hari. Lama melaut ditentukan berdasarkan jumlah es yang dibawa dan keberadaan ikan. Faktor es menjadi penting karena sifat ikan tuna mudah rusak yang akan menentukan harga jual. Berdasarkan sifatnya ikan tuna dapat yang melakukan migrasi jarak jauh (migratory species) dari samudera pasifik ke samudera hindia dan sebaliknya. Hal tersebut menyebabkan pola penangkapan ikan tuna di Kota Bitung dibedakan menjadi tiga musim penangkapan yaitu musim puncak, peralihan, dan paceklik.

Perbedaan musim juga didasarkan kepada pengalaman penangkapan ikan tuna oleh nelayan di Kelurahan Batu Lubang, namun sebenarnya tidak ada patokan yang pasti kapan musim puncak maupun musim paceklik tiba, karena kenyataan yang terjadi bahwa seringkali nelayan tidak dapat hasil tangkapan yang memuaskan pada saat musim puncak. Waktu penangkapan ikan tuna juga dipengaruhi oleh keadaan posisi bulan. Pada saat posisi bulan penuh (purnama), kecenderungan penangkapan mengalami peningkatan hasil dan pada bulan mati mengalami penurunan hasil. Tabel 2 memperlihatkan kecenderungan musim penangkapan ikan di Kota Bitung. Menurut Uktolseja et al. (1991) puncak musim penangkapan ikan untuk daerah di kawasan timur Indonesia (Sulawesi Utara dan Maluku) pada umumnya terjadi pada bulan April sampai dengan awal Bulan Oktober. Hal tersebut menunjukan bahwa telah terjadi perubahan puncak musim penangkapan ikan terutama ikan tuna di kawasan Laut Sulawesi.

Biaya operasional merupakan seluruh biaya yang dikeluarkan karena berlangsungnya proses produksi yang terdiri dari biaya tetap dan biaya tidak tetap (Choliq et al. 1999). Jenis biaya tetap (fixed cost) pada usaha penangkapan ikan tuna terdiri dari biaya pemeliharaan kapal, mesin, peralatan tangkap dan biaya penyusutan dimana sebagian besar biaya tersebut dikeluarkan oleh pemilik kapal. Pengeluaran biaya tetap tersebut merupakan hasil kesepakatan antara pemilik kapal dan pekerjanya. Pemeliharaan kapal dilakukan rata - rata selama tiga kali per tahun yang terdiri dari pergantian kayu kapal yang sudah mulai rusak, pembersihan kapal dari organisme yang menempel dan pengecatan kapal. Biaya pemeliharaan mesin yang dikeluarkan terdiri dari biaya penggantian oli mesin, servis

Tabel 2. Kalender Musim Penangkapan Ikan Tuna Berdasarkan Persepsi Nelayan di Kelurahan Batu Lubang Kota Bitung, 2011.

Table 2. Tuna Fishing Season Calendar Based on Fisher's Perceptions in the Batu Lubang Village of Bitung City, 2011.

\begin{tabular}{llccccc}
\hline No & Musim / Season & $\begin{array}{c}\text { Hari per trip / } \\
\text { Day per trip }\end{array}$ & $\begin{array}{c}\text { Trip per Bulan / } \\
\text { Trip per month }\end{array}$ & \multicolumn{3}{c}{ Bulan / Month } \\
\hline 1. & Puncak / Peak & $4-14$ & $1-4$ & & 4-6 & 7-10 \\
\hline 2. & Peralihan / Transitional & $3-10$ & $2-4$ & & \\
3. & Paceklik / Bad & $3-14$ & $1-4$ & & \\
\hline
\end{tabular}

Sumber: Data Primer, 2011 (diolah) / Source: Primary data, 2011 (processed) 
mesin dan spare part mesin. Pemilik kapal memberikan perhatian yang lebih terhadap pemeliharaan kapal dan mesin ini karena untuk keselamatan para pekerjanya pada saat melakukan operasi penangkapan ikan tuna.

Biaya tidak tetap (variable cost) yang dikeluarkan terdiri dari biaya operasional penangkapan dan biaya perbekalan/ ransum. Biaya operasional terbesar yang dikeluarkan adalah biaya bahan bakar minyak dan biaya es. Dalam satu kali trip penangkapan, armada penangkapan membutuhkan bahan bakar minyak sebanyak 100 - 700 liter dan es balok sebanyak $20-160$ balok es.

Tabel 3 dan 4 menunjukan struktur pembiayaan dan penerimaan usaha penangkapan ikan berdasarkan perbedaan musim dan perbedaan aset ukuran kapal dimana terdapat kecenderungan peningkatan biaya usaha pada saat musim paceklik ikan. Hal tersebut dikarenakan bertambahnya jumlah hari melaut (day per trip) nelayan untuk melakukan aktivitas penangkapan. Selain itu, lokasi penangkapan ikan (fishing ground) kecenderungannya juga semakin jauh pada saat musim paceklik, karena nelayan berusaha terus untuk mendapatkan ikan.

Total biaya yang dikeluarkan oleh kapal berukuran 5 - 10 GT lebih besar hampir dua kalinya dibandingkan dengan kapal berukuran < 5 GT. Begitu pula dengan hasil penerimaannya yaitu hampir dua kali lipat dari kapal berukuran < 5 GT. Hal tersebut menunjukan bahwa kebutuhan biaya dan penerimaan usaha penangkapan ikan tuna dipengaruhi oleh besarnya ukuran kapal yang digunakan.

Tabel 3. Struktur Pembiayaan dan Penerimaan Usaha Penangkapan Ikan Tuna Ukuran Kapal < 5 GT, di Kelurahan Batu Lubang Kota Bitung Berdasarkan Musim, 2011.

Table 3. Revenue and Cost Structure of Tuna Fishing of Fleet Size <5GTin Batu Lubang Village of Bitung City According to Season, 2011.

\begin{tabular}{|c|c|c|c|c|c|}
\hline \multirow[b]{2}{*}{ No } & \multirow[b]{2}{*}{$\begin{array}{l}\text { Jenis Analisa Usaha / } \\
\text { Business Analysis }\end{array}$} & \multicolumn{3}{|c|}{ Musim / Season } & \multirow[b]{2}{*}{$\begin{array}{l}\text { Total / } \\
\text { Total }\end{array}$} \\
\hline & & $\begin{array}{l}\text { Puncak / Peak } \\
\text { (Rp. / IDR.) }\end{array}$ & $\begin{array}{l}\text { Peralihan / } \\
\text { Transitional } \\
\text { (Rp. / IDR.) }\end{array}$ & $\begin{array}{l}\text { Paceklik / Bad } \\
\text { (Rp. / IDR.) }\end{array}$ & \\
\hline \multirow[t]{3}{*}{1.} & Total biaya / Total cost & $29,789,946$ & $31,578,990$ & $32,384,913$ & $93,753,849$ \\
\hline & A. Biaya tetap / Fixed cost & $3,473,742$ & $3,473,742$ & $3,473,742$ & $10,421,225$ \\
\hline & $\begin{array}{l}\text { B. Biaya tidak tetap / } \\
\text { Variable cost }\end{array}$ & $26,316,205$ & $28,105,248$ & $28,911,171$ & $83,332,625$ \\
\hline 2. & Penerimaan / Revenue & $174,377,700$ & $63,569,250$ & $27,564,000$ & $265,510,950$ \\
\hline 3. & $\begin{array}{l}\text { Keuntungan armada / } \\
\text { Net income per fleet }\end{array}$ & $144,587,754$ & $31,990,260$ & $-4,820,913$ & $171,757,101$ \\
\hline 4. & $\begin{array}{l}\text { Bagi hasil pemilik / } \\
\text { Sharing net income owner }\end{array}$ & $68,679,183$ & $15,195,374$ & $-2,289,934$ & $81,584,623$ \\
\hline 5. & $\begin{array}{l}\text { Bagi hasil nahkoda / } \\
\text { Sharing net income captain }\end{array}$ & $18,073,469$ & $3,998,783$ & $-602,614$ & $21,469,637$ \\
\hline 6. & $\begin{array}{l}\text { Bagi hasil / Sharing net } \\
\text { income the crew }\end{array}$ & $14,458,775$ & $3,199,026$ & $-482,091$ & $17,175,710$ \\
\hline
\end{tabular}

Sumber: Data Primer, 2011 (diolah) / Source: Primary data, 2011 (processed) 
Tabel 4. Struktur Pembiayaan dan Penerimaan Usaha Penangkapan Ikan Tuna Ukuran Kapal 5 - 10 GT di Kelurahan Batu Lubang Kota Bitung Berdasarkan Musim, 2011.

Table 4. Revenue and Cost Structure of Tuna Fishing Fleet Size 5-10 GT in the Batu Lubang Village Bitung City According to Season, 2011.

\begin{tabular}{|c|c|c|c|c|c|}
\hline \multirow[b]{2}{*}{ No } & \multirow[b]{2}{*}{$\begin{array}{c}\text { Jenis Analisa Usaha / } \\
\text { Business Analysis }\end{array}$} & \multicolumn{3}{|c|}{ Musim / Season } & \multirow[b]{2}{*}{$\begin{array}{c}\text { Total / } \\
\text { Total }\end{array}$} \\
\hline & & $\begin{array}{l}\text { Puncak / Peak } \\
\text { (Rp. / IDR.) }\end{array}$ & $\begin{array}{l}\text { Peralihan / } \\
\text { Transitional } \\
\text { (Rp. / IDR.) }\end{array}$ & $\begin{array}{l}\text { Paceklik / Bad } \\
\text { (Rp. / IDR.) }\end{array}$ & \\
\hline \multirow[t]{3}{*}{1.} & Total biaya / Total cost & $58,619,426$ & $58,803,763$ & $60,153,659$ & $177,576,848$ \\
\hline & A. Biaya tetap / Fixed cost & $8,572,817$ & $8,572,817$ & $8,572,817$ & $25,718,452$ \\
\hline & $\begin{array}{l}\text { B. Biaya tidak tetap / } \\
\text { Variable cost }\end{array}$ & $50,046,609$ & $50,230,946$ & $51,580,841$ & $151,858,397$ \\
\hline 2. & Penerimaan / Revenue & $259,196,625$ & $138,048,000$ & $60,662,588$ & $457,907,213$ \\
\hline 3. & $\begin{array}{l}\text { Keuntungan armada / } \\
\text { Net income per fleet }\end{array}$ & $200,577,199$ & $79,244,237$ & 508,929 & $280,330,364$ \\
\hline 4. & $\begin{array}{l}\text { Bagi hasil pemilik / } \\
\text { Sharing net income owner }\end{array}$ & $95,274,169$ & $37,641,012$ & 241,741 & $133,156,923$ \\
\hline 5. & $\begin{array}{l}\text { Bagi hasil nahkoda / } \\
\text { Sharing net income captain }\end{array}$ & $25,072,150$ & $9,905,530$ & 63,616 & $35,041,296$ \\
\hline 6. & $\begin{array}{l}\text { Bagi hasil / Sharing net } \\
\text { income the crew }\end{array}$ & $20,057,720$ & $7,924,424$ & 50,893 & $28,033,036$ \\
\hline
\end{tabular}

Sumber: Data Primer, 2011 (diolah) / Source: Primary data, 2011 (processed)

Ikan tuna merupakan komoditas ikan ekspor yang harganya dipengaruhi oleh nilai kurs mata uang dolar. Permintaan ikan tuna yang berasal dari Kota Bitung cukup tinggi, sehingga produksi ikan yang dilakukan oleh nelayan selalu terserap di pasar. Penerimaan usaha pada saat musim puncak ikan berkisar antara Rp. 170 - 250 juta (sekitar tiga kali penerimaan pada saat musim paceklik).
Pada saat musim paceklik, usaha perikanan mengalami kerugian dikarenakan biaya total yang dikeluarkan tidak dapat tertutupi dari hasil penangkapan. Nilai penerimaan usaha perikanan tangkap tuna dipengaruhi oleh banyaknya ikan, kualitas ikan dan harga ikan. Kualitas ikan tuna yang dihasilkan dibedakan menjadi 5 macam, yaitu ikan tuna ekor kuning (Yellow fin) jenis A, B, C, Lokal dan Reject (Tabel 5).

Tabel 5. Harga Ikan Tuna Ekor Kuning di Kelurahan Batu Lubang Kota Bitung Berdasarkan Kualitas , 2011.

Table 5. Price of Yellow Fins Tuna in the Batu Lubang Village of Bitung City Based on Quality, 2011.

\begin{tabular}{clccc}
\hline No & $\begin{array}{l}\text { Kelas Ikan Tuna Ekor Kuning / } \\
\text { Yellow Fin Tuna Based on Class }\end{array}$ & $\begin{array}{c}\text { Selang Harga Ikan / } \\
\text { Range of Fish Price (Rp. / IDR.) }\end{array}$ \\
\hline 1. & Kelas A / Class A & 35,000 & - & 38,000 \\
2. & Kelas B / Class B & 30,000 & - & 32,000 \\
3. & Kelas C / Class C & 22,000 & - & 27,000 \\
4. & Kelas lokal / Class local & 12,000 & - & 13,000 \\
5. & Kelas rusak / Class reject & 8,000 & - & 10,000 \\
\hline
\end{tabular}

Sumber: Data Primer, 2011 (diolah) / Source: Primary data, 2011 (processed) 
Tabel 6. Analisa Ekonomi Usaha Penangkapan Ikan Tuna Berdasarkan Ukuran Kapal di Kelurahan Batu Lubang Kota Bitung , 2011.

Table 6. Economic Analysis of Tuna Fishing Based on Fleet Size in the Batu Lubang Village Bitung City, 2011.

\begin{tabular}{clcc}
\hline No & \multicolumn{1}{c}{$\begin{array}{c}\text { Analisa Ekonomi Usaha / } \\
\text { Business Economy Analysis }\end{array}$} & $\begin{array}{c}\text { Kapal < 5 GT/ } \\
\text { Fleet < 5 GT }\end{array}$ & $\begin{array}{c}\text { Kapal 5 - 10 GT / } \\
\text { Fleet 5 - 10 GT }\end{array}$ \\
\hline 1. & Rasio kelayakan usaha / RC Ratio & 2.83 & 2.58 \\
2. & Rasio pengembalian investasi / Pay back period (PP) & 0.32 & 0.75 \\
3. & Rasio laba atas usaha / Return of investment (ROI) & 3.09 & 1.33 \\
\hline
\end{tabular}

Sumber: Data Primer, 2011 (diolah) / Source: Primary data, 2011 (processed)

Kualitas ikan yang baik akan mendorong meningkatkan harga, namun harga yang diterima nelayan dapat dipermainkan oleh karyawan pematok harga pada perusahaan penampung ikan tuna yang disebut sebagai ceker. Modusnya adalah ikan kualitas A dihargai kualitas B dan kualitas B dihargai kualitas C. Kejadian tersebut terjadi apabila nelayan yang menyetor hasil tangkapannya ke perusahaan penampung tidak memiliki pengetahuan yang cukup terkait kualitas ikan tuna.

\section{Prospek Pengembangan Usaha Penangkapan Ikan Tuna}

Prospek pengembangan usaha penangkapan ikan tuna dilihat berdasarkan analisa finansial (Tabel 6). Hasil analisa finansial pada kedua ukuran kapal menunjukan bahwa usaha perikanan tangkap tuna di Kelurahan Batu Lubang layak untuk dikembangkan secara ekonomi, namun armada kapal < 5 GT lebih baik dibandingkan dengan kapal 5-10 GT. Rasio kelayakan usaha pada kapal < 5 GT menunjukan nilai 2, 83 yang berarti bahwa setiap biaya Rp. 1 yang dikeluarkan akan mendapatkan penerimaan sebesar Rp. 2, 83. Rasio pengembalian investasi sebesar 0,32 tahun menunjukan bahwa investasi yang telah dikeluarkan dapat kembali selama \pm 4 bulan saja. Rasio laba atas usaha sebesar 3,09 menunjukan bahwa untuk setiap investasi sebesar Rp. 1 akan menghasilkan laba sebesar Rp. 3.09.

\section{KESIMPULAN DAN IMPLIKASI KEBIJAKAN}

\section{Kesimpulan}

Kesimpulan yang dapat diambil dalam penulisan makalah ini adalah:

1. Kebutuhan investasi total armada penangkapan ikan tuna di Kota Bitung ukuran kapal < 5 GT adalah sebesar \pm Rp. 33.000.000 sedangkan untuk kapal berukuran 5 - 10 GT adalah sebesar \pm Rp. 140.000.000. Biaya investasi terbesar adalah biaya investasi kapal dengan bermesin dalam.

2. Struktur pembiayaan usaha armada penangkapan ikan tuna di Kota Bitung berdasarkan musim menunjukan bahwa nilai biaya total mengalami kecenderungan peningkatan pada saat musim paceklik ikan dan penerimaan usaha mengalami kecenderungan peningkatan pada saat musim puncak ikan.

3. Struktur pembiayaan usaha armada penangkapan ikan tuna di Kota Bitung berdasarkan ukuran kapal menunjukan hubungan positif ukuran kapal yang digunakan dengan biaya total, penerimaan usaha dan pendapatan usaha yang diterima.

4. Prospek pengembangan usaha penangkapan ikan tuna yang dibedakan berdasarkan ukuran kapal menunjukan bahwa ukuran kapal < 5 GT memiliki 
prospek pengembangan usaha yang lebih baik dibandingkan dengan ukuran kapal 5-10 GT. Hal tersebut dapat dilihat berdasarkan nilai rasio kelayakan usaha, rasio pengembalian investasi dan rasio laba atas usaha.

\section{Implikasi Kebijakan}

Implikasi kebijakan yang dapat dilakukan oleh pemangku kepentingan baik pemerintah daerah dan pemerintah pusat diantaranya adalah:

1. Menciptakan iklim usaha investasi yang baik untuk penangkapan ikan tuna dengan batasan ukuran kapal berskala kecil yaitu 5 - 10 GT.

2. Meningkatkan ketersediaan informasi yang cukup terkait dengan struktur penerimaan dan biaya yang dibutuhkan dalam melakukan investasi penangkapan ikan tuna bagi para investor yang ingin menanamkan modalnya.

3. Menjembatani antara investor yang ingin menanamkan modalnya dengan masyarakat nelayan lokal yang telah memiliki pengalaman usaha di penangkapan tuna untuk meningkatkan efisiensi hasil tangkapan melalui konsep mitra usaha dengan prinsip bagi hasil yang adil.

4. Pengadaan rumpon ikan tuna untuk pelaku usaha penangkapan yang belum memiliki rumpon melalui skema kelompok usaha bersama (KUB) maksimal 5 armada penangkapan ikan tuna skala 5-10 GT.

5. Membentuk satuan pengelola informasi harga ikan tuna khusus pada wilayah Kota Bitung dan selalu menginformasikan kepada nelayan tuna agar tidak terjadi penipuan harga yang dilakukan oleh karyawan perusahaan penampung tuna.

\section{DAFTAR PUSTAKA}

Anonim. 2012. Laporan Data Statistik Perikanan Tahun 2011. Dinas Kelautan dan Perikanan Kota Bitung.

Apsari, W. 2009. Kontribusi Sub Sektor Perikanan Terhadap Perkembangan Perekonomian Kota Bitung Periode 2000 - 2007. Fakultas Ekonomi dan Manajemen. Institut Pertanian Bogor (IPB). Bogor. Hal 2.

Choliq, A.R., Wirasmita, dan O. Sofwan. 1999. Evaluasi Proyek (Suatu Pengantar). Pionir Jaya. Bandung. Hal 33 - 41

Dahuri, R. 2008. Restrukturisasi Manajamen Perikanan Tuna. Majalah Samudera Online. (68). Desember.

Fauzi, A. 2001. Prinsip - Prinsip Penelitian Sosial Ekonomi: Panduan Singkat. Jurusan Sosial Ekonomi Perikanan dan Kelautan. Institut Pertanian Bogor (IPB). Bogor

Marcille, J., T. Boely, M. Unar, G.S. Merta, B. Sadhotomo, and J.C.B. Uktolseja. 1984. Tuna Fishing In Indonesia. Editions de I'ORSTOM. http://www. horizon.documentation.ird.fr/exl-doc/ pleins_textes/pleins_textes_5/pt5/ travaux_d/17342.pdf. Diakses tanggal 23 November 2012.

Nugraha, B. dan E. Rahmat. 2008. Status Perikanan Huhate (Pole and Line) di Bitung, Sulawesi Utara. Jurnal Penelitian Perikanan Indonesia Volume 14 No 3 Tahun 2008. Badan Riset Kelautan dan Perikanan. Hal $311-318$.

Poernomo, R.P. 2006. "Profil Tuna Indonesia". Dalam Fuad Cholik, Shidiq Moeslim, Endang Sri Heruwati, Taufik Ahmad, dan Ahmad Jauzi (Eds), 60 Tahun Perikanan Indonesia. Masyarakat Perikanan Nusantara. Jakarta. Halaman $153-164$

Riyanto, B. 2001. Dasar-Dasar Pembelanjaan Perusahaan. BPFE Yogyakarta. Yogyakarta. Hal 327 - 336. 
Soekartawi. 2003. Agribisnis Teori dan Aplikasinya. PT Raja Grafindo Persada. Jakarta. Hal $218-220$.

Soeratno dan L. Arsyad. 2003. Metodologi Penelitian untuk Ekonomi dan Bisnis. UPP AMP YKPN. Yogyakarta. Hal 256

Suharno dan H. Santoso. 2008. Model Permintaan Yellowfin Segar Indonesia di Pasar Jepang. Buletin Ekonomi Perikanan Volume VIII No 2 Tahun 2008. http: http://www.medpet. journal.ipb.ac.id/index.php/bulekokan/ article/view/2735/1719. Diakses tanggal 23 November 2012
Uktolseja, J. C. B., B. Gafa, S. Bahar, dan E. Mulyadi. 1991. Potensi dan Penyebaran Sumberdaya Ikan Tuna dan Cakalang (Katsuwonus pelamis). Dalam: Potensi dan Penyebaran Sumberdaya Ikan Laut di Perairan Indonesia. Direktorat Jenderal Perikanan. Pusat Penelitian dan Pengembangan Perikanan. Pusat Penelitian dan Pengembangan Oseanologi. Lembaga Ilmu Pengetahuan Indonesia. Jakarta. Hal. $29-43$. 